\title{
Metaphors in English News Headlines
}

\author{
Bei Chen
}

City College of Wuhan University of Science and Technology, Wuhan 430083, China.

chenbeikerry@hotmail.com

\begin{abstract}
The essay introduces metaphors in English news headlines. The essay collects data from authoritative American newspapers The New York Times. In accordance with the classification of Lakoff and Johnson (structural metaphors, orientational metaphors and ontological metaphors), the essay analyzes the specific metaphorical expression in English news headlines as well as the overlapping of the three metaphor types. The study can help English-learners better understand metaphors in English news headlines, thus they can grasp the main idea of a piece of news in a very short time.
\end{abstract}

Keywords: metaphors, news headlines, source domain, target domain.

\section{Introduction}

Metaphors have been a heated topic in recent years. Originally a rhetorical tradition, now it has become an important cognitive tool. The essence of metaphors is to understand one thing in terms of the others. A metaphor is the mapping from the source domain to the target domain based on the similarities between two domains. Metaphors can be classified into structural metaphors, orientational metaphors and ontological metaphors.

In accordance with the classification of Lakoff and Johnson (structural metaphors, orientational metaphors and ontological metaphors) [1], the thesis analyzes the specific metaphorical expression in English news headlines as well as the overlapping of the three metaphor types.

\section{Research Background}

Metaphor has been studied for more than two thousand years since the ancient Greece in the West and the Pre-Qin periods (2696-221 BC) in China [2]. As far as metaphor researchers are concerned, there are "depreciators" and "appreciators". Plato, who held the opinion that metaphor and other figures of speech were just artful talk which was opposed to the aim of philosophy, is the representative of the "depreciators". Among the "appreciators", there are Aristotle, Quintillian, P. Fantanier, Richards, R. Jakobson, P. Ricoeur, G. Lakoff \& M. Johnson. They have contributed a lot to metaphorical study.

\subsection{The Rhetorical Tradition}

Metaphor has been regarded as just a figure of speech from 300 B.C. to 1930s. In western countries, the systematic study on metaphor can be traced back to more than 2000 years ago. It is widely agreed that the serious study of metaphor started from Aristotle. The rhetorical tradition of metaphor has been based on the concept's "similarity" or "comparison" between the literal and the figurative meaning of an expression. More specifically, metaphor has been seen as a three-item pattern involving the elements "tenor", "vehicle" and "ground" [3], A metaphor expresses the unfamiliar (the tenor) in terms of the familiar (the vehicle). When William Shakespeare wrote "All the world's a stage", "stage" is the vehicle for "world", the tenor.

\subsection{Semantic View of Metaphors}

1700 s and 1800s witnessed constant attacks from philosophers on metaphors. They argued that metaphors destroyed communication for it would easily result in the misunderstanding of a word's true meaning. People didn't pay special attention to metaphor until 1900s. From 1930s to the early 1970s, semantic research on metaphor developed greatly. British Philosophy and linguist Richards put forward to the theory of "Semantic Interaction". He claimed that metaphor is the interaction 
between tenor and vehicle. The tension between tenor and vehicle pushes the reader to explore the meaning of metaphor from this interaction. American philosopher and logician Max Black revised and developed the interaction theory of metaphor, emphasizing the roles of the users of language (including speaker and listener) in the process of metaphor's use and explanation [4]. Their study in metaphors is expanded from the rhetorical level to a semantic level.

\subsection{Cognitive View of Metaphors}

In 1980, Lakoff and Johnson systematically analyzed metaphor in their masterpiece Metaphors We Live By. In this book, they point out metaphor is pervasive in everyday life, not just in language but also in thought and action. Metaphor is not the invention of those great poets, but a normal manner in which people understand the world. Our ordinary conceptual system, in terms of which we both think and act, is fundamentally metaphorical in nature. The way we think, what we experience, and what we do every day is very much a matter of metaphor. Lakoff and Johnson's conceptual metaphor theory provides a new understanding of metaphor. From this point of view, metaphors of cognitive linguistics are mapping from a model in one domain to a corresponding structure in another domain. Metaphors help us understand the abstract conceptual domains correctly and expand our knowledge to a new domain.

In this book, Lakoff and Johnson put forward the theory of "conceptual metaphor" and classified conceptual metaphor as structural metaphor, ontological metaphor and orientational metaphor. Then Lakoff further points out that metaphor is the mapping from one conceptual domain to another conceptual domain. With this mapping, we can use the language in the source domain and the structure of inference to construct and understand the target domain. The mapping of metaphor is not random but derived from our experience and daily life. It is the outcome of people's cognition activity. Once a metaphor mapping is constructed, people will continuously look for various new connections between the two domains and establish different relations between them. This provides us a new approach to understand things and a new method to reorganize the world, which deepens our understanding of the world. It is vital to our apprehending the world, forming concepts, developing knowledge, conducting mental activity and making inferences [5].

\subsection{The Types of Metaphors}

Wang Yin introduced a number of classification standards of metaphors from different perspectives. Black classified metaphors into extinct metaphors, dormant metaphors and active metaphors; Lakoff \& Johnson classified metaphors into structural metaphors, orientational metaphors and ontological metaphors according to the different source domains. This essay is based on the classification made by Lakoff \& Johnson.

\section{Metaphors in English News Headlines}

A headline is the refining of a news report. Audience of traditional media often firstly look at the news headline to make sure whether they would like to go on reading the content of the news report. If time is limited, they would select news to read according to the headline of it. In this information technology era, only when a reader is interested in the news headline, will he click the link to read the whole news report. Therefore, in order to attract readers to read the news report to an extreme, to have an important impact on the spreading efficiency of news, an author will adopt a variety of approaches to make the headline more vivid. Metaphor is one of the most frequently used rhetorical devices to enhance effect of expression and efficiency of spreading. Then a glimpse will be taken at the metaphors in the news headlines in New York Times [6].

\subsection{Structural Metaphors in English News Headlines}

Structural metaphors refer to the cases where one concept is metaphorically structured in terms of another. In a structural metaphor, one complex concept (usually abstract) is presented in terms of some other (usually more concrete) concept. For example, in the structural metaphor TIME IS 
MONEY, concepts from the source domain TIME are transferred to the target domain MONEY, because money is visible in human life and therefore quite concrete and easier to understand. Here, the concept TIME is understood in terms of the concept MONEY. A number of elements of the concept MONEY are mapping onto the concept TIME systematically: we understand and experience time as the kind of thing that can be spent, wasted, invested wisely or poorly, budgeted, saved or squandered. The two professors give several examples of expressions reflecting the metaphorical concept TIME IS MONEY, such as "You're wasting my time" and "I've invested a lot of time in her".

On the international edition of The New York Times published on Wednesday, June 13, 2018, there is a report entitled A Voracious Appetite for Art, interviews some billionaire art collectors who often buy at Art Basel. This headline contains a typical structural metaphor. In it, the metaphorical concept is ART IS FOOD. The mapping from the source domain onto the target domain in this metaphor can be illustrated in the following table:

Table 1. Art is food

\begin{tabular}{|c|c|}
\hline Source domain & Target domain \\
\hline Art & Food \\
\hline Desire to buy art works & appetite \\
\hline artists & chefs \\
\hline
\end{tabular}

On The New York Times published on May 30, 2016, a report is entitled From the Seeds of the Arab Spring, a Harvest of Dystopian Fiction. A typical structural metaphor is contained in this headline. The report introduces a phenomenon that a number of dystopian fictions have emerged in Arabian countries in recent years. The source domain in this metaphor is a field of crops. Seeds are sowed; fruits are harvested. "Seeds" in the target domain is a series of anti-government movement with the theme of "democracy" and "economy", which is called "Arab Spring". Several years after the movement, the situation of these countries still hasn't been improved. People there who were expectant are now extremely disappointed. At this time, many dystopian fictions are published in these Arabian countries, which are the reflection of the writers' feeling. They describe the terrible political reality through the forms of science fictions and surrealism, which is the fruit of the "seeds" of Arab Spring. Readers grasp the similarities between source domain and target domain to understand the connotation of the metaphor, thus they can understand the main purpose of this report.

\subsection{Orientational Metaphors in English News Headlines}

Orientational metaphors refer to metaphors which involve spatial orientation (e.g., UP-DWON, ON-OFF, FRONT-BACK, IN-OUT, DEEP-SHALLOW, CENTER-EDGE). The source domain for orientational metaphors is space. by mapping an orientational concept onto a non-orientational concept, orientational metaphors make the non-spatial concept more easily understood. Orientational metaphors come from the interaction between human being and nature. They are the metaphors which people early shape in mind and can be understood without difficulties. Based on these concepts, we map the abstract concepts like feelings, health, number, social status to the concrete orientational terms. We'd notice that these metaphorical concepts are not arbitrary but rather cultural and language specific.

The conceptual metaphor HIGH STATUS IS UP; LOW STATUS IS DOWN is put forward by Lakoff and Johnson (1980). The social and physical basis of this metaphor is that "status is correlated with (social) power and (physical) power is up". This metaphor is contained in the news headline Admit it: The economy under Trump is not bad on the international edition of The New York Times published on Wednesday, June 13, 2018. Donald Trump is the current president of the US, thus he is the person with the biggest power in the country. The concept that US is under Trump actually contains the conceptual metaphor mentioned above.

Another orientational metaphor can be found in the headline Species on the Brink, which appears on the The New York Times published on Wednesday, June 13, 2018. The conceptual metaphor used 
here is IN IS INCLUDED, OUT IS EXCLUDED. The meaning of brink is "edge"; "species on the brink" here refers to species that are about to die out.

\subsection{Ontological Metaphors in English News Headlines}

Ontological metaphors allow us to view something abstract such as events, activities, emotions, etc., as something concrete, entities and substances.

On The New York Times published on Wednesday, June 13, 2018, there is a report entitled Study Puts A Price Tag on Violence in Brazil, which reports a study measuring the economic impact of violence in Brazil. The action "put a price tag" in the title is metaphorical, which refers to the calculation of economic loss caused by violence in Brazil.

Another report in the same newspaper has a headline Putin's Gamble: A Showcase for Russia, comparing Word Cup 2018 with a showcase for Putin to show that his country is "open and transparent". With this metaphor, something abstract become more concrete and understandable.

On The New York Times published on May 27, 2016, there is a report with the headline Subways in the Northeast Are Showing Their Age. The report puts forward the recurring problems with the subways in Northeast American cities like New York, Washington D.C. and Boston. In the metaphor, the source domain is human being and the target domain is subways in Northeast America. The similarity between them is that they become worn out as they grow old. Personification is one type of ontological metaphors.

\section{Summary}

Metaphors make news headline more concise and vivid. Studying the metaphors in English news headlines will help average readers to comprehend new things and grasp the main idea of a report promptly via metaphorical thought.

\section{References}

[1]. Lakoff, G., M. Johnson. Metaphors We Live By, The University of Chicago Press, 1980. p.102110.

[2]. Shu Dingfang, Studies in Metaphor, Shanghai Foreign Language Education Press,2000, p.15-18.

[3]. Geoffrey N. Leech, Linguistic Guide to English Poetry, Longman, 1979, p29-32.

[4]. Peng Zengan, New Perspective of Metaphor Study, Shandong Art Press, 2006, p170-178.

[5]. Wang Yin, Cognitive Linguistics, Shanghai Foreign Language Education Press,2006, p 409-410.

[6]. Information on: www.nytimes.com. 